\title{
Mapping of five genes from human chromosome 17 to chromosome $h n$ of the common shrew Sorex araneus
}

\author{
Denis M. LARKIN, Oleg L. SEROV and Natalia S. ZHDANOVA
}

Larkin D. M., Serov O. L. and Zhdanova N. S. 2000. Mapping of five genes from human chromosome 17 to chromosome $h n$ of the common shrew Sorex araneus. [In: Evolution in the Sorex araneus group: Cytogenetic and molecular aspects. J. B. Searle and J. M. Wójcik, eds]. Acta Theriologica 45, Suppl. 1: 143-146.

Comparative mapping shows that the syntenic gene group which is located on human chromosome 17 (HSA17) is preserved in most mammalian species. Insectivores (including shrews) appear to be closer to the ancestral eutherians than other mammalian orders. That is why common shrews are of special interest for the study of mammalian genome evolution. A set of human, mouse and bovine PCR primers previously used for mapping the bovine homologue of HSA17 was applied to the mapping effort in shrews. Three of 21 primer pairs tested yielded a single PCR product of expected size. Additionally, we have developed consensus PCR primers for GLUT4 based on human, mouse and porcine sequences, and for THRA1 using human and porcine sequences. As a result, genes for NF1, MYL4, THRA1, GLUT4 and MPO were assigned to shrew chromosome $h n$ (SARhn) using a set of shrew-mouse somatic hybrids. PCR products of shrew THRA1 and MPO were partially sequenced and showed $95 \%$ homology to sheep THRA1 and $91 \%$ homology to human MPO sequences respectively with the NCBI BLAST program. The data obtained confirm the homology between HSA17 and SARhn revealed by zoo-FISH analysis. It is suggested this syntenic group was present in the ancestral mammalian founder karyotype.

Institute of Cytology and Genetics, Russian Academy of Sciences, Novosibirsk 630090, Russia, e-mail: lark@bionet.nsc.ru

Key words: Sorex araneus, comparative mapping, PCR, hybrid cells

\section{Introduction}

Zoo-FISH analysis as well as direct physical or linkage mapping has shown a remarkable conservation of some syntenic gene associations during mammalian evolution. In particular, the gene association located on human chromosome 17 has been found as a single chromosome in all eutherians tested except for a few rodents, primates and the possum (Jauch et al. 1992, Wakefield and Graves 1996, Davisson et al. 1998). In dogs this group is presented as two blocks of conserved synteny (Werner et al. 1997). The localization of two genetic markers and zoo-FISH analysis suggested the conservation of the human chromosome 17 gene association to the common shrew (Sorex araneus) chromosome $h n$, precisely to its $h$-arm (Pack et al. 1995, Malchenko et al. 1996, Dixkens et al. 1998). In this work we apply a zoo-PCR approach to map human chromosome 17 genes in $S$. araneus. For the analysis we 
used PCR primers designed to amplify the conservative regions of homologous genes in other species. We tested a set of 21 heterologous PCR primer pairs previously used for mapping the bovine homologue of human chromosome 17 (Yang and Womack 1995, 1997, 1998) and 10 additional pairs which we have designed for comparative mapping in pigs. As a result of these tests, and subsequent mapping using shrew $\times$ mouse hybrid clones, we present the localization of 5 genes in S. araneus.

\section{Material and methods}

\section{Marker development}

A set of loci from human chromosome 17 was selected to be assigned in $S$. araneus. The sequences of the PCR primers used successfully to amplify the loci in this study are shown in Table 1. The primer sets for GLUT4 and THRA1 were designed from porcine, mouse or human cDNA sequences for the genes published in GeneBank with the use of the PrimerSelect program (Lasergene99 package) whereas the primers for MYL4 and NF1 were the same as those originally designed to amplify bovine sequences from these genes. The primers for $M P O$ are a consensus, designed to amplify the sequence from this gene in different mammals (Lyons et al. 1997).

\section{PCR analysis}

PCR conditions were optimized to amplify shrew-specific fragments with each primer set by varying annealing temperature and extension time. Genomic DNA (20ng) from shrew and mouse were amplified in 25-l reactions containing $0.1 \mathrm{nM}$ of each dNTP, $0.2 \mu \mathrm{M}$ of each primer, 1.5-2.0 $\mu \mathrm{M}$ of $\mathrm{MgCl}_{2}$ and 0.5 units of Taq DNA polymerase in 1PCR buffer $(65 \mathrm{mM}$ Tris- $\mathrm{HCl} \mathrm{pH} 8.0 ; 16 \mathrm{mM}$ $\left.\left(\mathrm{NH}_{4}\right)_{2} \mathrm{SO}_{4}\right)$. PCR amplifications were performed in Biometra thermocyclers with the following conditions: $95^{\circ} \mathrm{C}$ for $3 \mathrm{~min}$, followed by $35-45$ cycles of $95^{\circ} \mathrm{C}$ for $0.5 \mathrm{~min}, 55-61^{\circ} \mathrm{C}$ for $1 \mathrm{~min}$ and $72^{\circ} \mathrm{C}$ for $1-1.5 \mathrm{~min}$.

PCR products were subjected to gel electrophoresis in ethidium bromide-stained agarose gels (1.5-4.0\%) in $1 \times$ TBE buffer. Shrew PCR fragments for THRA1 and MPO were directly cycle sequenced by the standard Sanger dydeoxy method according to the Pharmacia Biotech protocol.

Table 1. Details of the PCR primers successfully used in this study.

\begin{tabular}{|c|c|c|c|c|}
\hline Loci & $\begin{array}{l}\text { Human } \\
\text { localization }\end{array}$ & Primer pairs sense/antisense & Origin & References \\
\hline GLUT4 & $17 \mathrm{p} 13$ & $\begin{array}{l}\text { 5 GATCTCAGCCGTCTTCC } \\
5 \text { CAGCCCAGTGTTTACAGG }\end{array}$ & $\begin{array}{l}\text { Porcine } \\
\text { cDNA }\end{array}$ & \\
\hline$M P O$ & $17 q 23.1$ & $\begin{array}{l}5 ` \text { CCACACCCTCATCCAACC } \\
5 ` \text { GCTCCCGGATCTCATCC }\end{array}$ & CATS & Lyons et al. 1997 \\
\hline MYL4 & 17q21-qter & $\begin{array}{l}\text { 5`TTTCCCGCAACAAGGAGCAG } \\
\text { 5 'GGTTGGGAAGAACTTTGAAGAGG }\end{array}$ & $\begin{array}{l}\text { Mouse } \\
\text { cDNA }\end{array}$ & Yang and Womack 1995 \\
\hline THRA1 & $17 q 11.2-q 12$ & $\begin{array}{l}\text { 5`ACGCCAGCCGCTTCCTCCAC } \\
5 ` \text { CCCCCGCCTCCCACACTG }\end{array}$ & $\begin{array}{l}\text { Porcine } \\
\text { cDNA }\end{array}$ & \\
\hline NF1 & $17 q 11.2$ & $\begin{array}{l}\text { 5`TGCCCATGAGACACTCGTTTG } \\
\text { 5`CTTGGTGGAGTCCAGTGAGGTG }\end{array}$ & $\begin{array}{l}\text { Bovine } \\
\text { cDNA }\end{array}$ & Yang and Womack 1995 \\
\hline
\end{tabular}


Table 2. Shrew $\times$ mouse somatic cell hybrids: presence/absence of NF1, MPO, GLUT4, THRA1 and MYL4 amplifications. ${ }^{\text {a }}$ - presence (+) or absence (-) of amplifications.

\begin{tabular}{llccccc}
\hline Clone & Shrew chromosomes & NF $1^{a}$ & MPO & GLUT4 & THRA1 & MYL4 \\
\hline C2-1 & $h n$ & + & + & + & + & + \\
C2-3 & $b c, i k, j l, h n, m p, r, t u$ & + & + & + & + & + \\
C2-9 & $i k, g o, h n, q r$ & + & + & + & + & + \\
K2-1 & $h n$ & + & + & + & + & + \\
K2-1BS & - & - & - & - & - & - \\
\hline
\end{tabular}

Homology with previously sequenced genes from the GenBank database was determined using the NCBI BLAST program.

Somatic cell hybrids. The establishment of a Sorex araneus $\times$ mouse somatic cell hybrid panel was described by Pack et al. (1995). In this study a variety of shrew $\times$ mouse clones containing $h n$ were used (Table 2). DNA extracted from shrew and mouse liver was used to distinguish shrew and mouse amplifications in clones.

\section{Results and discussion}

For our studies on the common shrew, we tested a set of 31 human, mouse, bovine and porcine heterologous primers (Yang and Womack 1995, Lyons et al. 1997, Yang and Womack 1997). PCR conditions for amplifying shrew-specific markers useful for synteny mapping were optimized for all 5 loci. All these markers were assigned to shrew chromosome $h n$ using shrew $\times$ mouse hybrid clones. Other PCR primer pairs either did not amplify single shrew sequences or shrew and mouse PCR products were indistinguishable under the conditions used.

The PCR fragment of shrew THRA1 showed 95\% homology with the sheep THRA1 sequence, and the shrew MPO fragment showed 91\% homology with the human $M P O$ sequence.

The localization of 5 human chromosome 17 markers to chromosome $h n$ of the common shrew (NF1, GLUT4, MYL4, MPO and THRA1) span almost fully the length of chromosome 17 except for the terminal region of the $p$ arm. The data obtained are in complete correlation with the results of zoo-FISH analysis which showed homology of the distal part of the $h$ arm of shrew chromosome $h n$ and human chromosome 17 (Dixkens et al. 1998).

In most mammals examined human chromosome 17 is presented as a single block of conserved synteny with the exception of some primates and rodents (Jauch et al. 1992, Davisson et al. 1998). Breaking of gene synteny was also shown for the possum and the dog (Wakefield and Graves 1996, Werner et al. 1997). In some cases these breaks are presented by single markers (mouse, possum), which are located on chromosomes not apparently homologous to human chromosome 17. Such small changes in gene synteny could not be revealed by zoo-FISH analysis and need direct linkage or physical mapping. 
In this paper we have shown the possibility of the zoo-PCR approach to genome mapping in $S$. araneus. It can strongly accelerate the gene mapping in shrews, making the shrew genome map a more useful tool for the analysis of mammalian evolution. In our work the proportion of heterologous primers which work in shrews is lower than found for other species - about 17\% instead of the usual $30 \%$ (Lyons et al. 1997). This may be connected with the specific set of primers used. We did not test a random set of heterologous primers but mostly those which amplify bovine and porcine genes.

Mapping of 5 genes to chromosome $h n$ increases the number of genes assigned to the $S$. araneus map up to 42 .

Acknowledgements: We thank Dr J. Womack of Texas A\&M University who kindly provided us with a set of bovine PCR primers, and L. Matyakhina of Institute of Cytology and Genetics, Novosibirsk, Russia. This study was supported by a grant from Russian Foundation for Basic Researches (99-04-49979).

\section{References}

Davisson M., Bradt D., Merriam J., Rockwood S. and Eppig J. 1998. The Mouse Gene Map. Institute for Laboratory Animal Research Journal 39: 96-131.

Dixkens C., Klett C., Bruch J., Kollak A., Serov O. L., Zhdanova N., Vogel W. and Hameister H. 1998. ZOO-FISH analysis in insectivores: "Evolution extols the virtue of the status quo". Cytogenetics and Cell Genetics 80: 61-67.

Jauch A., Wienberg J., Stanyon R., Arnold N., Tofanelli S., Ishida T. and Cremer T. 1992. Reconstruction of genomic rearrangements in great apes and gibbons by chromosome painting. Proceedings of the National Academy of Sciences of the USA 89: 8611-8615.

Lyons L. A., Laughlin T. F., Copeland N. G., Jenkins N. A., Womack J. E. and O’Brien S. J. 1997. Comparative anchor tagged sequences (CATS) for integrative mapping of mammalian genomes. Nature Genetics 15: 47-56.

Malchenko S. N., Koroleva I. V., Brusgaard K., Matyakhina L. D., Colonin M. G., Pack S. D., Searle J. B., Borodin P. M., Serov O. L. and Bendixen C. 1996. Chromosome localization of the gene for growth hormone in the common shrew (Sorex araneus). Hereditas 125: 243-245.

Pack S. D., Kolonin M. G., Borodin P. M., Searle J. B. and Serov O. L. 1995. Gene mapping in the common shrew (Sorex araneus; Insectivora) by shrew- rodent cell hybrids: chromosome localization of the loci for HPRT, TK, LDHA, MDH1, G6PD, PGD, and ADA. Mammalian Genome 6: 784-787.

Wakefield M. J. and Graves J. M. 1996. Comparative maps of vertebrates. Mammalian Genome 7: 715-716.

Werner P., Raducha M. G., Prociuk U., Henthorn P. S. and Patterson D. F. 1997. Physical and linkage mapping of human chromosome 17 loci to dog chromosomes 9 and 5. Genomics 42: 74-82.

Yang Y. P. and Womack J. E. 1995. Human chromosome 17 comparative anchor loci are conserved on bovine chromosome 19. Genomics 27: 293-297.

Yang Y. P. and Womack J. E. 1997. Construction of a bovine chromosome 19 linkage map with an interspecies hybrid backcross. Mammalian Genome 8: 262-266.

Yang Y. P. and Womack J. E. 1998. Parallel radiation hybrid mapping: a powerful tool for high-resolution genomic comparison. Genome Research 8: 731-736.

Received 30 September 1999, accepted 3 February 2000. 